\title{
CT Texture Analysis Potentially Predicts Local Failure in Head and Neck Squamous Cell Carcinoma Treated with Chemoradiotherapy
}

\author{
(D). Kuno, (DM.M. Qureshi, (DM.N. Chapman, DB. Li, (D).C. Andreu-Arasa, DK. Onoue, (D).T. Truong, and (D). Sakai
}

\begin{abstract}
BACKGROUND AND PURPOSE: The accurate prediction of prognosis and failure is crucial for optimizing treatment strategies for patients with cancer. The purpose of this study was to assess the performance of pretreatment CT texture analysis for the prediction of treatment failure in primary head and neck squamous cell carcinoma treated with chemoradiotherapy.
\end{abstract}

MATERIALS AND METHODS: This retrospective study included 62 patients diagnosed with primary head and neck squamous cell carcinoma who underwent contrast-enhanced CT examinations for staging, followed by chemoradiotherapy. CT texture features of the whole primary tumor were measured using an in-house developed Matlab-based texture analysis program. Histogram, gray-level cooccurrence matrix, gray-level run-length, gray-level gradient matrix, and Laws features were used for texture feature extraction. Receiver operating characteristic analysis was used to identify the optimal threshold of any significant texture parameter. We used multivariate Cox proportional hazards models to examine the association between the CT texture parameter and local failure, adjusting for age, sex, smoking, primary tumor stage, primary tumor volume, and human papillomavirus status.

RESULTS: Twenty-two patients (35.5\%) developed local failure, and the remaining 40 (64.5\%) showed local control. Multivariate analysis revealed that 3 histogram features (geometric mean [hazard ratio $=4.68, P=.026$ ], harmonic mean [hazard ratio $=8.61, P=.004$ ], and fourth moment [hazard ratio $=4.56, P=.048]$ ) and 4 gray-level run-length features (short-run emphasis [hazard ratio $=3.75, P=.044$ ], gray-level nonuniformity [hazard ratio $=5.72, P=.004$ ], run-length nonuniformity [hazard ratio $=4.15, P=.043$ ], and short-run low gray-level emphasis [hazard ratio $=5.94, P=.035]$ ) were significant predictors of outcome after adjusting for clinical variables.

CONCLUSIONS: Independent primary tumor CT texture analysis parameters are associated with local failure in patients with head and neck squamous cell carcinoma treated with chemoradiotherapy.

ABBREVIATIONS: CRT = chemoradiotherapy; GLCM = gray-level co-occurrence matrix; GLN = gray-level nonuniformity; GLRL = gray-level run-length; HNSCC = head and neck squamous cell carcinoma; HPV = human papillomavirus; HR = hazard ratio; RLN = run-length nonuniformity; SRE = short-run emphasis; SRLGE = short-run low gray-level emphasis

$C^{\mathrm{h}}$ hemoradiotherapy (CRT) is the mainstay of treatment for early and locally advanced head and neck squamous cell carcinoma (HNSCC). The accurate prediction of prognosis and failure is crucial for optimizing treatment strategies for patients with cancer; however, it remains an area of ongoing controversy. Cur-

Received March 6, 2017; accepted after revision July 16.

From the Departments of Radiology (H.K., M.M.Q., M.N.C., B.L., V.C.A.A., K.O., M.T.T., O.S.), Radiation Oncology (M.M.Q., M.T.T., O.S.), and Otolaryngology-Head and Neck Surgery (O.S.), Boston Medical Center, Boston University School of Medicine, Boston, Massachusetts; and Department of Diagnostic Radiology (H.K.), National Cancer Center Hospital East, Kashiwa, Chiba, Japan.

Please address correspondence to Osamu Sakai, MD, PhD, Department of Radiology, Boston Medical Center, Boston University School of Medicine, FGH Building, 3rd Floor, 820 Harrison Ave, Boston, MA 02118; e-mail: osamu.sakai@bmc.org

三Indicates article with supplemental on-line table and appendix.

Indicates article with supplemental on-line photo.

http://dx.doi.org/10.3174/ajnr.A5407 rently, the American Joint Committee on Cancer staging system, which uses unidimensional tumor size, local anatomic invasion, nodal involvement, and the presence of metastatic disease, is the most widely accepted and applied prognostic system in cancer management. Yet this classification is mainly based on surgical criteria rather than predictors of radiation or chemotherapy response, and this tumor node metastasis information sometimes fails to predict the response to nonsurgical therapy. Several studies have demonstrated a significant impact of primary tumor volume on treatment outcome in patients with HNSCC treated with radiation therapy. ${ }^{1-5}$ More recent studies have also shown that patients with human papillomavirus (HPV)-positive HNSCCs have a better response to CRT than patients with HPV-negative tumors. ${ }^{6-9}$ However, treatment failure still occurs in patients with HNSCC with small tumor volume and/or HPV-positive status. ${ }^{10}$ 
Image texture is defined as a complex visual pattern within an image, consisting of simpler subpatterns with characteristic features, and texture analysis allows the mathematic detection of the subtle spatial arrangement of the gray level among image pixels. ${ }^{11,12}$ Texture analysis is a postprocessing technique and a new addition to the image-analysis armamentarium that extracts information native to image data that is not apparent on visual inspection of images. These techniques ultimately provide a quantitative means of extracting image features that are useful for comparative analyses. In the past several years, CT texture analysis has been investigated in oncology imaging for its ability to predict treatment outcome in patients with nonsmall cell lung cancer, esophageal cancer, and metastatic renal cell carcinoma. ${ }^{13-18}$ One study showed that CT texture and histogram analysis parameters of the primary mass were associated with overall survival in patients with HNSCC who were treated with induction chemotherapy followed by chemotherapy, radiation, and/or an operation. ${ }^{19}$ However, it is still unclear whether CT texture analysis can predict local failure to radiation therapy in patients with HNSCC, including with important clinical factors such as smoking history, tumor volume, and HPV status. Considering that texture analysis may detect subtle pathologic changes in an image, ${ }^{20,21}$ we herein hypothesized that texture analysis on CT would enable assessment of radiosensitivity in a patient with HNSCC.

The purpose of this study was to assess the utility of texture analysis for the prediction of treatment failure in primary HNSCC treated with CRT.

\section{MATERIALS AND METHODS \\ Patients}

The institutional review board at Boston Medical Center approved this study. The requirement to obtain written informed consent was waived for this retrospective analysis.

Between February 2008 and February 2015, one hundred sixty-five consecutive newly diagnosed patients with histologically proved HNSCCs (oropharynx, larynx, hypopharynx, and oral cavity) underwent contrast-enhanced CT before treatment. Eighty-six of the 165 patients (52\%) were excluded because they were treated surgically. We excluded an additional 13 patients: 3 patients due to significant artifacts from motion or dental hardware on CT that may have influenced the texture analysis, 5 patients with very small primary tumors (tumor volume $<0.4 \mathrm{~cm}^{3}$ ) that were difficult to contour, and 5 patients due to an inability to complete treatment. Three patients showing local control were excluded because follow-up periods were $<12$ months due to other causes of death (2 patients) or transfer to hospice care for distant metastatic disease. One patient who developed metachronous multiple HNSCC was also excluded due to additional treatment with CyberKnife stereotactic radiosurgery (Accuray, Sunnyvale, California) in the same region for a secondary squamous cell carcinoma. The remaining 62 patients ( 53 men, 9 women; age $31-80$ years; median age, 58 years) diagnosed with primary HNSCC were enrolled in this study. Of 62 patients, 31 (50\%) had oropharyngeal squamous cell carcinomas, 9 (15\%) had hypopharyngeal squamous cell carcinomas, 19 (31\%) had laryngeal squamous cell carcinomas, and 3 (5\%) had oral cavity squamous cell carcinomas.

\section{Treatment and Follow-Up}

All patients were treated with definitive intensity-modulated radiation therapy. The primary gross tumor volume was treated to a median dose of $69.96 \mathrm{~Gy}$ (range, 60.0-69.96 Gy), over a median of 33 fractions (range, 30-33 fractions) and a median of 47 days (range, 40-102 days). Concurrent chemotherapy was given to 60 (96.8\%) patients, but 1 patient was changed to radiation therapy alone due to stomatitis. Of these 60 patients, 33 also received induction chemotherapy. The remaining 2 patients underwent radiation therapy alone.

Patients were followed after the conclusion of treatment to evaluate local control. All patients were followed clinically for at least 12 months after completion of radiation therapy. The follow-up evaluation included physical and endoscopic examinations. In addition to the clinical examination, CT, MR imaging, and $\left[{ }^{18} \mathrm{~F}\right]$ FDG PET/CT were used to assess the clinical response as part of standard treatment care. Local failures were confirmed by biopsy except in cases of significant progressive disease by clinical examination and imaging assessment with $\left[{ }^{18} \mathrm{~F}\right]$ FDG PET/CT or MR imaging. The follow-up period was designated as the total time of follow-up, starting at treatment initiation and ending either at histologically confirmed local failure or at last patient contact without local failure.

\section{CT Imaging Protocol}

Contrast-enhanced CT examinations were performed either independently or combined with $\left[{ }^{18} \mathrm{~F}\right]$ FDG PET examination, acquired by 64- or 16-detector row CT scanners (LightSpeed VCT or Discovery STE-16 PET/CT; GE Healthcare, Milwaukee, Wisconsin). Dedicated neck CT studies were helically acquired (120 $\mathrm{kV}$ [peak], gantry rotation time $=0.5$ second, automatic tube current modulation on with $10 \%$ adaptive statistical iterative reconstruction, helical pitch factor $=0.937: 1$, scan FOV $=300 \mathrm{~mm}$, reconstructed section thickness $=1.25$ or $3.75 \mathrm{~mm}$, image matrix $=512 \times 512$ ) extending from the skull base to the thoracic inlet following a 60 -second delay after intravenous contrast injection (80-160 mL; ioversol, Optiray 350, Mallinckrodt, St. Louis, Missouri; or iopamidol, Isovue 370, Bracco, Princeton, New Jersey). The images were reviewed in soft-tissue algorithms.

\section{Image Segmentation}

The primary tumor was manually contoured by a neuroradiologist with 9 years of experience who was blinded to patient history. Segmentation of the whole primary lesion for each section was performed with a dedicated AW workstation (GE Healthcare) with a semiautomated graphic user interface. We used axial images for the segmentation. If the tumor border was unclear on the axial images, coronal or sagittal reformatted sections were used to guide segmentation. We manually excluded obvious necrotic and cystic areas, regions of ulceration of the tumor, calcification, and areas of artifacts from the contoured tumor volume (On-line Figure). The most solid component of the tumor was contoured. When severe streak artifacts within the tumor were seen, we excluded the artifact section and used only artifact-free sections for texture analysis. The full processing time of image segmentation and texture analysis per subject was approximately 10 minutes.

AJNR Am J Neuroradiol 38:2334-40 Dec 2017 www.ajnr.org 
Table 1: Demographics and tumor characteristics of patients with head and neck cancer ${ }^{2}$

\begin{tabular}{|c|c|c|c|c|}
\hline Characteristic & $\begin{array}{l}\text { Overall Subjects } \\
\qquad(n=62)\end{array}$ & $\begin{array}{l}\text { Local Failure } \\
\qquad(n=22)\end{array}$ & $\begin{array}{l}\text { Local Control } \\
\qquad(n=40)\end{array}$ & $\begin{array}{c}P \\
\text { Value }\end{array}$ \\
\hline Age (yr) & & & & .205 \\
\hline Median (range) & $58(31-80)$ & $60(31-79)$ & $57(32-80)$ & \\
\hline Sex & & & & .098 \\
\hline Male & $53(85)$ & $21(95)$ & $32(80)$ & \\
\hline Female & $9(15)$ & $1(5)$ & $8(20)$ & \\
\hline Primary site & & & & .515 \\
\hline Oropharynx & $31(50)$ & $11(50)$ & $20(50)$ & \\
\hline Hypopharynx & $9(15)$ & $4(18)$ & $5(13)$ & \\
\hline Larynx & $19(31)$ & $5(23)$ & $14(35)$ & \\
\hline Oral cavity & $3(5)$ & $2(9)$ & $1(2)$ & \\
\hline T-Stage & & & & $.037^{\mathrm{b}}$ \\
\hline $\mathrm{Tl}$ & $1(2)$ & $0(0)$ & $1(2)$ & \\
\hline $\mathrm{T} 2$ & $14(23)$ & $2(9)$ & $12(30)$ & \\
\hline $\mathrm{T} 3$ & $18(29)$ & $8(36)$ & $10(25)$ & \\
\hline T4 & $29(47)$ & $12(55)$ & $17(43)$ & \\
\hline $\mathrm{N}$-stage & & & & .914 \\
\hline No & $9(15)$ & $3(14)$ & $6(15)$ & \\
\hline N1 & $10(16)$ & $3(14)$ & $7(18)$ & \\
\hline N2 & $39(63)$ & $14(64)$ & $25(63)$ & \\
\hline N3 & $4(6)$ & $2(9)$ & $2(5)$ & \\
\hline \multicolumn{5}{|l|}{ Histopathologic grade } \\
\hline Well diff. & $9(15)$ & $3(14)$ & $6(14)$ & .927 \\
\hline Moderately diff. & $33(53)$ & $13(59)$ & $20(50)$ & \\
\hline Poorly diff. & $17(27)$ & $6(27)$ & $11(28)$ & \\
\hline Unknown & $3(5)$ & 0 & $3(8)$ & \\
\hline Smoking (pack-year) & & & & .947 \\
\hline Median (range) & $20(0-100)$ & $30(0-100)$ & $20(0-60)$ & \\
\hline Tumor volume $(\mathrm{mL})$ & & & & $.007^{\mathrm{b}}$ \\
\hline Median (range) & $6.28(0.45-69.47)$ & $15.07(0.95-51.89)$ & $4.56(0.45-69.47)$ & \\
\hline HPV (p16) & & & & .917 \\
\hline Positive & $24(39)$ & $8(36)$ & $16(40)$ & \\
\hline Negative & $23(37)$ & $8(36)$ & $15(38)$ & \\
\hline Unknown & $15(24)$ & $6(27)$ & $9(23)$ & \\
\hline CT scanner & & & & .618 \\
\hline 64-detector row MDCT & $12(19)$ & $5(23)$ & $7(18)$ & \\
\hline 16-detector MDCT & $50(81)$ & $17(77)$ & $33(82)$ & \\
\hline Section thickness & & & & .689 \\
\hline $1.25 \mathrm{~cm}$ & $50(81)$ & $18(82)$ & $31(78)$ & \\
\hline $3.75 \mathrm{~cm}$ & $12(19)$ & $4(18)$ & $9(22)$ & \\
\hline ASIR & & & & .655 \\
\hline On & $22(35)$ & $7(32)$ & $15(38)$ & \\
\hline Off & $40(65)$ & $15(68)$ & $25(63)$ & \\
\hline
\end{tabular}

Note:-MDCT indicates multidetector row CT; ASIR, adaptive statistical iterative reconstruction; diff., differentiated squamous cell carcinoma.

${ }^{a}$ Data are presented as the number of patients with percentages in parentheses, unless otherwise noted.

${ }^{b}$ Indicates a significant difference by the Pearson $\chi^{2}$ or Mann-Whitney $U$ test $(P<.05)$

\section{Statistical Analysis}

First, associations of demographic and clinical characteristics with local control status were tested with the Pearson $\chi^{2}$ test or Mann-Whitney $U$ test. Texture parameters were then compared in patients with local control against patients who developed local failure using the Mann-Whitney $U$ test to select significant texture parameters. Second, receiver operating characteristic analysis was used to identify the optimal threshold of any significant texture parameter. The point on the receiver operating characteristic curve farthest from the 45degree reference line with the best combination of sensitivity and specificity was considered the optimum threshold. The area under the receiver operating characteristic curve was also measured for the selected parameters. Third, Cox proportional hazards models were used to examine the association between each selected CT texture parameter and local failure. The local control time was defined as the time between the start of treatment and the date on which local recurrence was found or the last followup. Furthermore, we used multivariate Cox proportional hazards models to examine the association between CT texture parameters and local failure, adjusting for age, sex, smoking (pack-year), primary tumor stage, primary tumor volume, and HPV status. Because 15 of 62 subjects had unknown HPV status, we used 47 subjects with HPV data for multivariate models.

All statistical analyses were performed by using STATA (Version 12.1; StataCorp, College Station, Texas). A $P$ value $<.05$ was considered statistically significant.

\section{Texture Analysis}

In this work, we measured 42 features from each segmented tissue volume using an in-house-developed Matlab (MathWorks, Natick, Massachusetts) texture analysis software. ${ }^{20,22}$ The mean value of the textural features on an ROI basis was estimated. The volume of each primary tumor was also calculated. The 42 features included the following:

1) Thirteen histogram features

2) Five gray-level co-occurrence matrix (GLCM) features

3) Eleven gray-level run-length (GLRL) features

4) Four gray-level gradient matrix features

5) Nine Laws features.

We discuss the extraneous math behind each texture feature in detail in a subsequent On-line Appendix. ${ }^{11,12,20,22-25}$

\section{RESULTS}

At a median follow-up of 29 months (range, 7-88 months) for included subjects, 22 patients (35.5\%) developed local failure and the remaining 40 patients (64.5\%) showed local control. The follow-up time of patients with local failure ranged from 3.7 to 14.4 months (median, 4.6 months), and the follow-up time of patients with local control ranged from 16.8 to 88.4 months (median, 35 months). Among 24 patients positive for HPV, 8 patients (33.3\%; 5 oropharynx, 2 larynx, and 1 oral tongue carcinoma) developed local failure. Complete patient demographics and tumor characteristics are described in Table 1. Primary tumor volume of the local control group was significantly smaller than that in the failure group (median, 4.56 versus $15.07 \mathrm{~mL}, P=.007)$. The primary T-stage was also significantly different between the local control and failure groups $(P=$ 
Table 2: Optimal thresholds obtained from ROC curves and sensitivity/specificity to predict local failure ${ }^{\mathrm{a}}$

\begin{tabular}{lclccccc}
\hline Texture Parameter & AUC & Cutoff Point & Sensitivity (\%) & Specificity (\%) & PPV (\%) & NPV (\%) & Accuracy (\%) \\
\hline Histogram & & & & & & \\
$\quad$ Mean & $0.67(0.54-0.81)$ & $>1102$ & $50.2(28.2-71.7)$ & $82.5(67.2-92.6)$ & 64.7 & 73.3 & 71.0 \\
SD & $0.70(0.56-0.84)$ & $<252.9$ & $40.9(20.7-63.7)$ & $92.5(79.6-98.4)$ & 74.0 & 75.0 & 74.2 \\
Geometric mean & $0.71(0.57-0.85)$ & $>920.6$ & $36.4(17.2-59.3)$ & $92.5(79.6-98.4)$ & 72.7 & 72.7 & 72.6 \\
$\quad$ Harmonic mean & $0.71(0.58-0.85)$ & $>243.4$ & $36.4(17.2-59.3)$ & $95.0(83.1-99.4)$ & 80.0 & 73.1 & 74.2 \\
Fourth moment & $0.69(0.55-0.83)$ & $<4.65 e 10$ & $40.9(20.7-63.6)$ & $92.5(79.6-98.4)$ & 74.0 & 75.0 & 74.2 \\
GLRL & & & & & & 73.1 & 74.2 \\
SRE & $0.79(0.68-0.91)$ & $<0.0341$ & $36.4(17.2-59.3)$ & $95.0(83.1-99.4)$ & 80.0 & 73.0 & 74.2 \\
LRE & $0.80(0.69-0.91)$ & $<0.0332$ & $63.6(40.7-82.8)$ & $80.0(64.4-90.9)$ & 63.6 & 80.0 \\
GLN & $0.80(0.69-0.92)$ & $<0.0408$ & $68.2(45.1-86.1)$ & $80.0(64.4-90.9)$ & 65.2 & 82.1 & 75.8 \\
RLN & $0.82(0.72-0.92)$ & $<0.0329$ & $77.3(58.8-87.3)$ & $77.5(54.6-92.2)$ & 65.4 & 86.1 & 77.4 \\
RP & $0.71(0.57-0.84)$ & $>433.3$ & $72.7(49.8-89.3)$ & $65.0(48.3-79.4)$ & 53.3 & 81.3 & 67.7 \\
LGRE & $0.73(0.60-0.85)$ & $>440$ & $81.8(59.7-94.8)$ & $62.5(45.8-77.3)$ & 54.6 & 86.2 & 69.4 \\
HGRE & $0.74(0.61-0.87)$ & $>433.9$ & $54.6(32.2-75.6)$ & $85.0(70.2-94.3)$ & 66.7 & 77.3 & 74.2 \\
SRLGE & $0.72(0.59-0.86)$ & $>444.2$ & $77.3(54.6-92.2)$ & $37.5(50.9-81.4)$ & 56.7 & 84.4 & 71.0 \\
\hline
\end{tabular}

Note:-LRE indicates long-run emphasis; RP, run percentage; LGRE, low gray-level run emphasis; HGRE, high gray-level run emphasis; PPV, positive predictive value; NPV, negative predictive value; AUC, area under the receiver operating characteristic curve; ROC, receiver operating characteristic.

a Numbers in parentheses are $95 \%$ confidence intervals.

${ }^{b}$ AUC of the RLN was significantly better than that of mean $(P=.022)$. The differences with other selected texture features were not significant $(P>.05)$.

Table 3: Cox proportional hazards model of selected CT texture parameters for predicting local failure

\begin{tabular}{|c|c|c|c|c|c|c|}
\hline \multirow[b]{2}{*}{ Texture Parameter } & \multicolumn{3}{|c|}{$\begin{array}{l}\text { Univariate Analysis } \\
\qquad(n=62)\end{array}$} & \multicolumn{3}{|c|}{$\begin{array}{c}\text { Multivariate Analysis }{ }^{a} \\
(n=47)\end{array}$} \\
\hline & HR & $95 \% \mathrm{Cl}$ & $P$ Value & HR & $95 \% \mathrm{Cl}$ & $P$ Value \\
\hline \multicolumn{7}{|l|}{ Histogram } \\
\hline Mean & 2.79 & $1.21-6.46$ & $.019^{\mathrm{b}}$ & 1.74 & $0.62-4.88$ & .295 \\
\hline SD & 5.69 & $2.39-13.53$ & $<.001^{\mathrm{b}}$ & 2.56 & $0.66-10.00$ & .176 \\
\hline Geometric mean & 4.08 & $1.50-11.07$ & $.002^{b}$ & 4.68 & $1.21-18.11$ & $.026^{\mathrm{b}}$ \\
\hline Harmonic mean & 3.47 & $1.17-10.26$ & $.012^{\mathrm{b}}$ & 8.61 & $2.00-37.19$ & $.004^{\mathrm{b}}$ \\
\hline Fourth moment & 5.69 & $2.40-13.53$ & $<.001^{\mathrm{b}}$ & 4.56 & $1.01-20.48$ & $.048^{\mathrm{b}}$ \\
\hline \multicolumn{7}{|l|}{ GLRL } \\
\hline SRE & 4.58 & $2.24-13.48$ & $<.001^{\mathrm{b}}$ & 3.75 & $1.23-13.61$ & $.044^{\mathrm{b}}$ \\
\hline LRE & 3.63 & $1.55-8.54$ & $.003^{b}$ & 2.68 & $0.67-10.66$ & .163 \\
\hline GLN & 5.61 & $2.06-15.28$ & $<.001^{\mathrm{b}}$ & 5.72 & $1.74-18.82$ & $.004^{\mathrm{b}}$ \\
\hline RLN & 5.69 & $2.22-14.59$ & $<.001^{\mathrm{b}}$ & 4.16 & $1.25-16.48$ & $.043^{\mathrm{b}}$ \\
\hline $\mathrm{RP}$ & 3.39 & $1.32-8.67$ & $.007^{\mathrm{b}}$ & 3.70 & $0.85-16.21$ & .082 \\
\hline LGRE & 5.06 & $1.71-14.99$ & $<.001^{\mathrm{b}}$ & 4.84 & $0.99-24.34$ & .055 \\
\hline HGRE & 3.74 & $1.61-8.69$ & $.003^{b}$ & 2.39 & $0.53-10.83$ & .260 \\
\hline SRLGE & 4.53 & $1.67-12.32$ & $.001^{\mathrm{b}}$ & 5.94 & $1.14-24.97$ & $.035^{b}$ \\
\hline
\end{tabular}

Note:- LRE indicates long-run emphasis; RP, run percentage; LGRE, low gray-level run emphasis; HGRE, high gray-level run emphasis.

a Models were adjusted for age, sex, smoking, primary tumor stage, primary tumor volume, and HPV status.

${ }^{\mathrm{b}}$ Indicates a significant difference $(P<.05)$

.037). There was no significant difference in the age $(P=.205)$, sex $(P=.098)$, primary site $(P=.515)$, N-stage $(P=.914)$, histopathologic grade $(P=.927)$, smoking pack-years $(P=.947)$, and HPV status $(P=.917)$ between the 2 groups. The distributions of the CT scanner, section thickness, and the use of adaptive statistical iterative reconstruction of these study subjects were not different between local control and failure groups $(P=.618$ for CT scanner, $P=.689$ for section thickness, and $P=.655$ for adaptive statistical iterative reconstruction).

Results of 42 texture parameters differentiating local control and local failure are shown in the On-line Table. The Mann-Whitney $U$ test revealed that 13 parameters, including 5 histogram features (mean, SD, geometric mean, harmonic mean, fourth moment) and 8 GLRL features (short-run emphasis [SRE], long-run emphasis, graylevel nonuniformity [GLN], run-length nonuniformity [RLN], run percentage, low gray-level run emphasis, high gray-level run emphasis, and short-run low gray-level emphasis [SRLGE]) showed significant differences between the local failure and local control groups.
The results of optimal thresholds for selected texture features obtained from receiver operating characteristic curves and sensitivity/specificity with area under the receiver operating characteristic curve to predict local failure are shown in Table 2. The highest area under the receiver operating characteristic curve was 0.82 , with a sensitivity of $77.3 \%$ and a specificity of $77.5 \%$ in RLN (one of the GLRL features). In subgroup analysis based on the HPV status, the area under the receiver operating characteristic curve was 0.80 , with a sensitivity of $87.5 \%$ and a specificity of $68.8 \%$ for the HPV-positive group and the area under the receiver operating characteristic curve was 0.75 with a sensitivity of $75.0 \%$ and a specificity of $73.3 \%$ for the HPV-negative group in RLN.

The results of Cox proportional hazards model of selected CT texture parameters and clinical factors for predicting local failure are shown in Table 3. The multivariate Cox proportional hazards model revealed that 3 histogram features [geometric mean (hazard ratio $[\mathrm{HR}]=4.68, P=.026)$, harmonic mean $(\mathrm{HR}=$ $8.61, P=.004)$, fourth moment $(\mathrm{HR}=4.56, P=.048)]$, and 4 GLRL features [SRE $(\mathrm{HR}=3.75, P=.044), \mathrm{GLN}(\mathrm{HR}=5.72$, $P=.004), \operatorname{RLN}(\mathrm{HR}=4.15 ; P=.043)$, and SRLGE $(\mathrm{HR}=$ 5.94, $P=.035)]$ remained significant predictors of outcome after adjusting for clinical variables. Representative examples of patients positive for HPV with oropharyngeal squamous cell carcinomas with local failure and local control are shown in the Figure.

\section{DISCUSSION}

In our study, we measured volumetric texture features of the whole primary HNSCC tumor using pretreatment contrast-enhanced CT. Three histogram features and 4 GLRL features have been associated with local failure in patients treated with CRT 

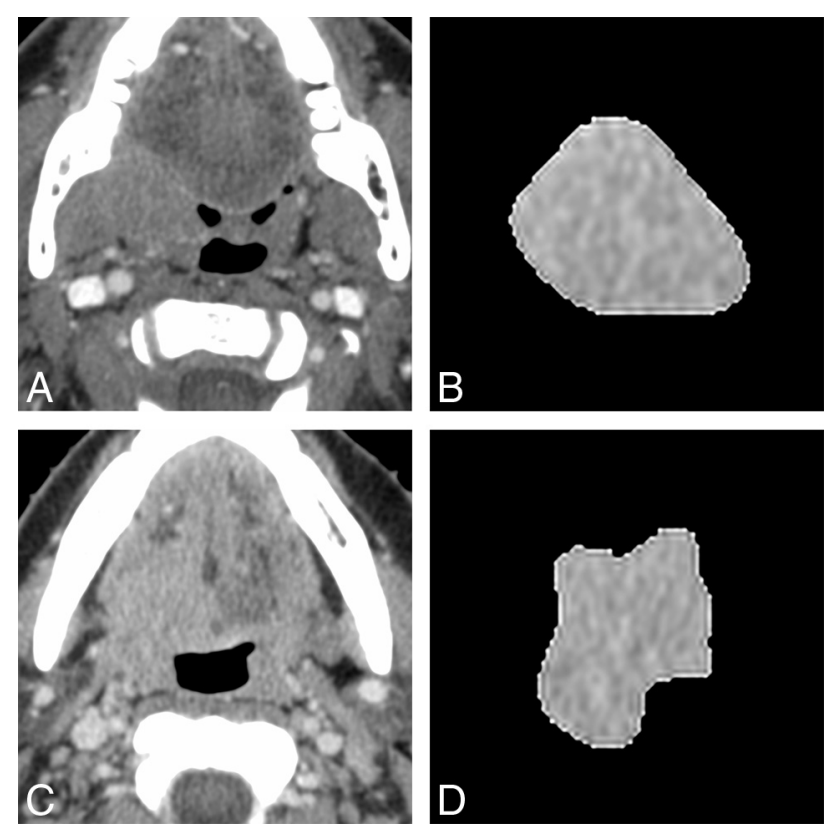

FIGURE. Representative axial contrast-enhanced CT images ( $A$ and $C$ ) and corresponding axial section ROI mask-segmented primary tumor $(B$ and $D$ ) for 2 different patients with oropharyngeal squamous cell carcinoma. Segmented tumor is from a 75-year-old man $(B)$ with right tonsil squamous cell carcinoma (HPV-positive; smoking, 0 pack-year; tumor volume, $16.4 \mathrm{~mL}$; clinical T-stage, T4) who developed local failure and a 43-year-old woman $(D)$ with squamous cell carcinoma of the right base of tongue (HPV- positive; smoking, 0 pack-year; tumor volume, $20.6 \mathrm{~mL}$; clinical T-stage, T4) who showed local control. Representative texture features of each patients are as follows; for geometric mean, 973.2 (local failure, B) and 906.6 (local control, D); for harmonic mean, 285.1 (local failure, $B$ ) and 210.3 (local control, D); for SRE, 0.026 (local failure, B) and 0.043 (local control, D); for GLN, 0.026 (local failure, $B$ ) and 0.042 (local control, D); for RLN, 0.019 (local failure, $B$ ) and 0.032 (local control, D); and for SRLGE, 479.1 (local failure, B) and 459.1 (local control, D).

after adjusting for clinical variables, including smoking history, HPV status, T-stage, and tumor volume. The results suggest that CT texture analysis may serve as an independent indicator of local failure regardless of tumor status, including HPV infection.

In recent years, the measurement of spatial heterogeneity by CT textural analysis has gained acceptance as a means to extract information from imaging of primary tumors to predict treatment outcome in oncology patients. ${ }^{13-18}$ In the head and neck, Zhang et $\mathrm{al}^{19}$ analyzed the predictive value of texture and histogram features in 72 patients with HNSCC treated with induction chemotherapy (TPF; docetaxel, cisplatin, and fluouracil) and found that in addition to expected factors such as tumor volume and $\mathrm{N}$ stage, primary mass entropy $(\mathrm{HR}=2.10$ for each 0.5 -unit increase; $P=.036$ ) and histogram skewness $(\mathrm{HR}=3.67$ for each 1.0 -unit increase; $P=.009)$ were independent predictors of overall survival in multivariate Cox regression analysis. However, their study included patients treated with an operation followed by chemotherapy, and HPV status was not provided in their analysis. In our study, we focused on the chemoradiosensitivity of the primary tumor using whole-tumor primary HNSCC volume texture analysis, and the results demonstrated that CT texture analysis parameters such as histogram and GLRL features are associated with local failure in patients with HNSCC treated with CRT.
The GLRL features are one of the categories of spatially dependent texture features based on the length and quantity of runs of adjacent pixels with similar intensity values. ${ }^{1,12,20}$ The significant difference in the texture features between local control and local failure groups suggests a different degree of uniformity within the tumors along both long and short matrix runs. Increased heterogeneity of the primary mass on contrast-enhanced CT images indicates that the tumor blood supply is heterogeneous, with some areas having increased vascular supply and others having hypoxic voids. ${ }^{26-29}$ Although there is no direct comparison between the underlying tumor histopathology and correlation to the mathematic significance of these features on texture analysis, the texture features may potentially reflect increased heterogeneity or hypoxic voids of the primary mass on contrast-enhanced CT images. ${ }^{19,30}$

Other pretreatment predictive imaging biomarkers of local control for HNSCC have been investigated using advanced imaging techniques, albeit with variable results. CT perfusion has been reported to obtain measures of tumor vascular physiology and hemodynamics, and some investigators demonstrated that CTdetermined tumor perfusion was an independent predictor of local control in HNSCC treated by definitive radiation therapy with or without chemotherapy. ${ }^{29,31-33}$ Diffusion-weighted imaging $^{34-37}$ and dynamic contrast-enhanced MR imaging ${ }^{38-41}$ have also been used as functional imaging techniques as predictive biomarkers of radiation therapy. One recently published study showed preliminary results exploring the value of assessing texture features with intratreatment dynamic contrast-enhanced MR imaging for patients with HNSCC. ${ }^{42}$ Functional imaging studies including perfusion are useful tools for mapping the vascularity of the tumor environment at baseline. However, these techniques are not routinely used in the clinical protocol for staging of HNSCC, and recently, there are increasing concerns for additional exposure to radiation or gadolinium-based contrast agents. ${ }^{43,44}\left[{ }^{18} \mathrm{~F}\right]$ FDG PET/CT is another imaging technique widely used in the evaluation of patients with HNSCC, and its clinical utility for predicting treatment outcome of HNSCC has been previously investigated. ${ }^{5,45-47}$ However, $\left[{ }^{18} \mathrm{~F}\right]$ FDG PET/CT examinations are used only in advanced-stage HNSCC when management may be altered due to detection of distant metastases. Contrast-enhanced CT is widely used to stage HNSCC before treatment; therefore, CT texture analysis could be potentially useful for predicting local failure without additional exposure to radiation or contrast material.

There are several limitations to this study. First, CT protocols including the types of CT scanners, section thickness, and adaptive statistical iterative reconstruction were not identical in this population, which may potentially affect the texture analysis. ${ }^{48}$ These problems remain to be solved in future validation studies using identical CT parameters. However, the distribution of subjects between local control and failure groups was almost the same for both types of CT scanners, different section thicknesses, and the use of adaptive statistical iterative reconstruction. Additionally, CT texture analysis parameters have been shown to be highly reproducible in multiple kilovolt peaks and milliampere-second settings in a water phantom. ${ }^{19}$ We therefore believe that the differences in scanners have little, if any, influence on our presented 
results. Second, a single user performed the semiautomated segmentation and workflow for this CT texture analysis. The generalizability of our results to other institutions and users is unknown, though the semiautomated nature of the software has the potential to reduce interobserver variation. Third, we contoured areas of obvious necrotic and cystic changes as well as ulceration out of the final contours that were imported into the texture analysis program, because including foci of air would not accurately reflect the underlying texture features within the solid portion of the tumors. However, the necrosis or ulceration within the tumor has a potential impact on hypoxia/radiosensitivity. This issue needs to be further evaluated in a future study assessing whether the region of necrosis should be included or excluded for texture analysis. Finally, the study subjects included heterogeneous groups of patients with HNSCC of different primary sites. Further studies with a larger number of patients are needed to validate the performance of the predictive model for each subsite.

\section{CONCLUSIONS}

Independent primary tumor CT texture analysis parameters are associated with local failure in patients with HNSCC treated with CRT. CT is noninvasive, widely available, and frequently used to stage early and locally advanced HNSCC before treatment. Therefore, CT texture analysis could serve as a widely applicable pretreatment noninvasive biomarker for predicting local failure with the potential to assist in treatment decisions in patients with HNSCC. Further testing using a larger sample size is needed to validate the performance of the predictive model.

Disclosures: Hirofumi Kuno_UNRELATED: Grants/Grants Pending: Grant-in-Aid for Young Scientists (B) KAKEN (No. 26861033), 2014-2015; Payment for Lectures Including Service on Speakers Bureaus: Toshiba Medical Systems, 2014. Osamu SakaiUNRELATED: Consultancy: Guerbet; Payment for Lectures Including Service on Speakers Bureaus: Bracco Diagnostics, Eisai.

\section{REFERENCES}

1. Studer G, Lütolf U, El-Bassiouni M, et al. Volumetric staging (VS) is superior to TNM and AJCC staging in predicting outcome of head and neck cancer treated with IMRT. Acta Oncol 2007;46:386-94 CrossRef Medline

2. Knegjens JL, Hauptmann M, Pameijer FA, et al. Tumor volume as prognostic factor in chemoradiation for advanced head and neck cancer. Head Neck 2011;33:375-82 CrossRef Medline

3. Strongin A, Yovino S, Taylor R, et al. Primary tumor volume is an important predictor of clinical outcomes among patients with locally advanced squamous cell cancer of the head and neck treated with definitive chemoradiotherapy. Int J Radiat Oncol Bio Phys 2012; 82:1823-30 CrossRef Medline

4. Doweck I, Denys D, Robbins KT. Tumor volume predicts outcome for advanced head and neck cancer treated with targeted chemoradiotherapy. Laryngoscope 2002;112:1742-49 CrossRef Medline

5. Romesser PB, Qureshi MM, Shah BA, et al. Superior prognostic utility of gross and metabolic tumor volume compared to standardized uptake value using PET/CT in head and neck squamous cell carcinoma patients treated with intensity-modulated radiotherapy. Ann Nucl Med 2012;26:527-34 CrossRef Medline

6. Lassen P, Eriksen JG, Hamilton-Dutoit S, et al; Danish Head and Neck Cancer Group (DAHANCA). HPV-associated p16-expression and response to hypoxic modification of radiotherapy in head and neck cancer. Radiother Oncol 2010;94:30-35 CrossRef Medline

7. Chung $\mathrm{CH}$, Zhang Q, Kong CS, et al. p16 protein expression and human papillomavirus status as prognostic biomarkers of nonoro- pharyngeal head and neck squamous cell carcinoma. J Clin Oncol 2014;32:3930-38 CrossRef Medline

8. Lassen P, Primdahl H, Johansen J, et al Danish Head and Neck Cancer Group (DAHANCA). Impact of HPV-associated p16-expression on radiotherapy outcome in advanced oropharynx and non-oropharynx cancer. Radiother Oncol 2014;113:310-16 CrossRef Medline

9. Huang SH, Xu W, Waldron J, et al. Refining American Joint Committee on Cancer/Union for International Cancer Control TNM stage and prognostic groups for human papillomavirus-related oropharyngeal carcinomas. J Clin Oncol 2015;33:836-45 CrossRef Medline

10. Vainshtein JM, Spector ME, McHugh JB, et al. Refining risk stratification for locoregional failure after chemoradiotherapy in human papillomavirus-associated oropharyngeal cancer. Oral Oncol 2014; 50:513-19 CrossRef Medline

11. Tang X. Texture information in run-length matrices. IEEE Trans Image Process 1998;7:1602-09 CrossRef Medline

12. Haralick RM, Shanmugam K, Dinstein IH. Textural features for image classification. IEEE Transactions on Systems, Man and Cybernetics 1973;3:610-21

13. Miles KA, Ganeshan B, Griffiths MR, et al. Colorectal cancer: texture analysis of portal phase hepatic CT images as a potential marker of survival. Radiology 2009;250:444-52 CrossRef Medline

14. Goh V, Ganeshan B, Nathan P, et al. Assessment of response to tyrosine kinase inhibitors in metastatic renal cell cancer: CT texture as a predictive biomarker. Radiology 2011;261:165-71 CrossRef Medline

15. Ganeshan B, Goh V, Mandeville HC, et al. Non-small cell lung cancer: histopathologic correlates for texture parameters at CT. $R a$ diology 2013;266:326-36 CrossRef Medline

16. Ng F, Ganeshan B, Kozarski R, et al. Assessment of primary colorectal cancer heterogeneity by using whole-tumor texture analysis: contrast-enhanced CT texture as a biomarker of 5-year survival. Radiology 2013;266:177-84 CrossRef Medline

17. Yip C, Landau D, Kozarski R, et al. Primary esophageal cancer: heterogeneity as potential prognostic biomarker in patients treated with definitive chemotherapy and radiation therapy. Radiology 2014;270:141-48 CrossRef Medline

18. Ganeshan B, Panayiotou E, Burnand K, et al. Tumour heterogeneity in non-small cell lung carcinoma assessed by CT texture analysis: a potential marker of survival. Eur Radiol 2012;22:796-802 CrossRef Medline

19. Zhang H, Graham CM, Elci O, et al. Locally advanced squamous cell carcinoma of the head and neck: CT texture and histogram analysis allow independent prediction of overall survival in patients treated with induction chemotherapy. Radiology 2013;269:801-09 CrossRef Medline

20. Buch K, Fujita A, Li B, et al. Using texture analysis to determine human papillomavirus status of oropharyngeal squamous cell carcinomas on CT. AJNR Am J Neuroradiol 2015;36:1343-48 CrossRef Medline

21. Fujita A, Buch K, Li B, et al. Difference between HPV-positive and HPV-negative non-oropharyngeal head and neck cancer: texture analysis features on CT. J Comput Assist Tomogr 2016;40:43-47 CrossRef Medline

22. Yu H, Buch K, Li B, et al. Utility of texture analysis for quantifying hepatic fibrosis on proton density MRI. J Magn Reson Imaging 2015; 42:1259-65 CrossRef Medline

23. Laws KI. Textured Image Segmentation [dissertation]. Los Angeles: University of Southern California; 1980

24. Castellano G, Bonilha L, Li LM, et al. Texture analysis of medical images. Clin Radiol 2004;59:1061-69 CrossRef Medline

25. Li B, Jara H, Yu H, et al. Enhanced Laws textures: a potential MRI surrogate marker of hepatic fibrosis in a murine model. Magn Reson Imaging 2017;37:33-40 CrossRef Medline

26. Nordsmark M, Overgaard M, Overgaard J. Pretreatment oxygenation predicts radiation response in advanced squamous cell carcinoma of the head and neck. Radiother Oncol 1996;41:31-39 Medline 
27. Janssen $\mathrm{H}$, Haustermans $\mathrm{K}$, Balm A, et al. Hypoxia in head and neck cancer: how much, how important? Head Neck 2005;27:622-38 CrossRef Medline

28. Nordsmark M, Bentzen SM, Rudat V, et al. Prognostic value of tumor oxygenation in 397 head and neck tumors after primary radiation therapy: an international multi-center study. Radiother Oncol 2005;77:18-24 CrossRef Medline

29. Hermans R, Meijerink M, Van den Bogaert W, et al. Tumor perfusion rate determined noninvasively by dynamic computed tomography predicts outcome in head-and-neck cancer after radiotherapy. Int $J$ Radiat Oncol Biol Phys 2003;57:1351-56 CrossRef Medline

30. Kassner A, Thornhill RE. Texture analysis: a review of neurologic MR imaging applications. AJNR Am J Neuroradiol 2010;31:809-16 CrossRef Medline

31. Zima A, Carlos R, Gandhi D, et al. Can pretreatment CT perfusion predict response of advanced squamous cell carcinoma of the upper aerodigestive tract treated with induction chemotherapy? AJNR Am J Neuroradiol 2007;28:328-34 Medline

32. Bisdas S, Nguyen SA, Anand SK, et al. Outcome prediction after surgery and chemoradiation of squamous cell carcinoma in the oral cavity, oropharynx, and hypopharynx: use of baseline perfusion CT microcirculatory parameters vs. tumor volume. Int J Radiat Oncol Biol Phys 2009;73:1313-18 CrossRef Medline

33. Truong MT, Saito N, Ozonoff A, et al. Prediction of locoregional control in head and neck squamous cell carcinoma with serial CT perfusion during radiotherapy. AJNR Am J Neuroradiol 2011;32: 1195-201 CrossRef Medline

34. Hatakenaka M, Nakamura K, Yabuuchi H, et al. Apparent diffusion coefficient is a prognostic factor of head and neck squamous cell carcinoma treated with radiotherapy. Jpn J Radiol 2014;32:80-89 CrossRef Medline

35. King AD, Chow KK, Yu KH, et al. Head and neck squamous cell carcinoma: diagnostic performance of diffusion-weighted MR imaging for the prediction of treatment response. Radiology 2013;266: 531-38 CrossRef Medline

36. Ohnishi K, Shioyama Y, Hatakenaka M, et al. Prediction of local failures with a combination of pretreatment tumor volume and apparent diffusion coefficient in patients treated with definitive radiotherapy for hypopharyngeal or oropharyngeal squamous cell carcinoma. J Radiat Res 2011;52:522-30 CrossRef Medline

37. Ng SH, Liao CT, Lin CY, et al. Dynamic contrast-enhanced MRI, diffusion-weighted MRI and (18)F-FDG PET/CT for the prediction of survival in oropharyngeal or hypopharyngeal squamous cell carcinoma treated with chemoradiation. Eur Radiol 2016;26:4162-72 CrossRef Medline

38. Ng SH, Lin CY, Chan SC, et al. Dynamic contrast-enhanced MR imaging predicts local control in oropharyngeal or hypopharyngeal squamous cell carcinoma treated with chemoradiotherapy. PLoS One 2013;8:e72230 CrossRef Medline

39. Chawla S, Kim S, Dougherty L, et al. Pretreatment diffusionweighted and dynamic contrast-enhanced MRI for prediction of local treatment response in squamous cell carcinomas of the head and neck. AJR Am J Roentgenol 2013;200:35-43 CrossRef Medline

40. Jansen JF, Schöder H, Lee NY, et al. Tumor metabolism and perfusion in head and neck squamous cell carcinoma: pretreatment multimodality imaging with $1 \mathrm{H}$ magnetic resonance spectroscopy, dynamic contrast-enhanced MRI, and [18 F]FDG-PET. Int J Radiat Oncol Biol Phys 2012;82:299-307 CrossRef Medline

41. Kim S, Loevner L, Quon H, et al. Prediction of response to chemoradiation therapy in squamous cell carcinomas of the head and neck using dynamic contrast-enhanced MR imaging. AJNR Am J Neuroradiol 2010;31:262-68 CrossRef Medline

42. Jansen JF, Lu Y, Gupta G, et al. Texture analysis on parametric maps derived from dynamic contrast-enhanced magnetic resonance imaging in head and neck cancer. World J Radiol 2016;8:90-97 CrossRef Medline

43. Kanda T, Ishii $\mathrm{K}$, Kawaguchi $\mathrm{H}$, et al. High signal intensity in the dentate nucleus and globus pallidus on unenhanced T1-weighted MR images: relationship with increasing cumulative dose of a gadolinium-based contrast material. Radiology 2014;270:834-41 CrossRef Medline

44. Kuno H, Jara H, Buch K, et al. Global and regional brain assessment with quantitative MR imaging in patients with prior exposure to linear gadolinium-based contrast agents. Radiology 2017;283:195204 CrossRef Medline

45. Chung MK, Jeong HS, Park SG, et al. Metabolic tumor volume of [18F]-fluorodeoxyglucose positron emission tomography/computed tomography predicts short-term outcome to radiotherapy with or without chemotherapy in pharyngeal cancer. Clin Cancer Res 2009;15:5861-68 CrossRef Medline

46. Kao CH, Lin SC, Hsieh TC, et al. Use of pretreatment metabolic tumour volumes to predict the outcome of pharyngeal cancer treated by definitive radiotherapy. Eur J Nucl Med Mol Imaging 2012;39:1297-305 CrossRef Medline

47. Hanamoto A, Tatsumi M, Takenaka Y, et al. Volumetric PET/CT parameters predict local response of head and neck squamous cell carcinoma to chemoradiotherapy. Cancer Med 2014;3:1368-76 CrossRef Medline

48. Buch K, Li B, Qureshi MM, et al. Quantitative assessment of variation in CT parameters on texture features: pilot study using a nonanatomic phantom. AJNR Am J Neuroradiol 2017;38:981-85 CrossRef Medline 